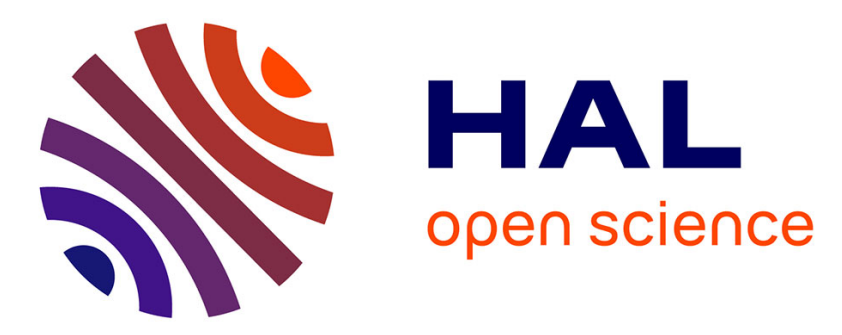

\title{
On the Feasibility of Power and Status Ranking in Traditional Setups
}

Petros Sekeris, Jean-Philippe Platteau

\section{To cite this version:}

Petros Sekeris, Jean-Philippe Platteau. On the Feasibility of Power and Status Ranking in Traditional Setups. Journal of Comparative Economics, 2010, 38 (3), pp.267-282. 10.1016/j.jce.2010.07.006 . halshs-00122421

\section{HAL Id: halshs-00122421 https://shs.hal.science/halshs-00122421}

Submitted on 1 Jan 2007

HAL is a multi-disciplinary open access archive for the deposit and dissemination of scientific research documents, whether they are published or not. The documents may come from teaching and research institutions in France or abroad, or from public or private research centers.
L'archive ouverte pluridisciplinaire HAL, est destinée au dépôt et à la diffusion de documents scientifiques de niveau recherche, publiés ou non, émanant des établissements d'enseignement et de recherche français ou étrangers, des laboratoires publics ou privés. 


\title{
On the Feasibility of Power and Status Ranking
}

\section{in Traditional Setups}

\author{
Jean-Philippe Platteau*and Petros G. Sekeris ${ }^{\dagger}$
}

November 2006

\begin{abstract}
This paper aims at a better understanding of the conditions under which unequal rank or power positions may get permanently established through asymmetric gift exchange when a gift brings pride to the donor and shame to the recipient. The central result obtained is that an asymmetric gift exchange equilibrium can occur only if the importance attached to social shame by a recipient is smaller than that attached to social esteem by a donor. Moreover, an income transfer is more likely to be traded against social esteem, status, or power when the weight put on these attributes by the donor or patron is higher. We also show that the recipient's productivity may take on a rather wide range of values in the domain of

${ }^{*}$ Centre for Research in the Economics of Development (CRED), Department of economics,

University of Namur, Rempart de la Vierge, 8 B-5000 Namur, Belgium. Corresponding author:

Jean-Philippe Platteau jean-philippe.platteau@fundp.ac.be

$\dagger$ Centre for Research in the Economics of Development (CRED)
\end{abstract}


feasibility of asymmetric gift exchange, and that, contrary to a commonly prevailing view, it is even possible that his productivity would be identical to that of the donor. Finally, the conditions are spelt out under which the recipient's effort is more likely to be reduced upon entering into asymmetric gift exchange relationships.

Keywords: Social esteem, status, power, patronage, gift exchange.

JEL classification: 012 ; O17 ; Z13 


\section{Introduction}

Gift exchange relationships, in contrast to market-mediated relationships, have attracted the attention of economists only recently. This new interest emerged, in particular, within the fields of development microeconomics and the economics of organizations understood as networks of agency relations or contracts. Drawing inspiration from anthropological writings dealing with gift exchange and reciprocity in traditional set-ups (see Platteau 1991, for a review), development economists have embarked upon devising and testing theories of reciprocal state-contingent transfers conceived as informal mutual insurance mechanisms (see, e.g., Kimball 1988; Fafchamps 1992; Coate and Ravallion 1993; Paxson 1993; Townsend 1994; Udry 1994; Morduch 1999; Dercon and Krishnan 2000; Ligon, Thomas and Worrall 2002). A quid pro quo is clearly involved in these voluntary transactions since, as pointed out by a renowned anthropologist a long time ago, 'everybody is thereby insured against hunger: he who is in need today receives help from him who may be in like need tomorrow' (Evans-Pritchard 1940: 85).

Labour relations or contracts provide another interesting application of the economics of reciprocity. Where effort and quality are difficult to monitor, an employer may pay workers wages exceeding the market-clearing levels in order to elicit effort and commitment from them. The extra wage is then conceived as a gift which the worker returns by providing adequate amounts of effort and attention (Akerlof 1982; Fehr, Kirchsteiger, and Riedl 1998; Fehr and Gächter 2000). As for Holmstrom and Milgrom (1991), they detect elements of discre- 
tionary gift exchanges in any fixed wage. Gift exchange takes on an intergenerational form when parents promise bequests (including inter-vivos transfers) to their children in the expectation to receive attention from them in their old age (Bernheim, Schleifer and Summers, 1985; Hoddinott, 1992; Cox and Rank, 1992; Barham et al., 1997; Johnson et al., 2001). In an alternative approach, individuals come to the help of their old parents in the hope that, through a sort of demonstration effect, their own children will behave likewise when they will themselves reach an advanced age (Cox and Stark, 2005).

A last illustration is the theory of gift exchange proposed by Aoki (2001) (see also Carmichael and MacLeod (1997) for an approach using evolutionary game theory), which is actually very close to the type of account most commonly encountered in the anthropological literature. In this approach, the gift serves both as a signal to communicate a willingness to cooperate to a potential partner, and as a commitment device since, once the gift has been made, the donator's interest is to abide by a contract provided that the partner also does it.

It is noteworthy that in all the above examples transactions appear to be motivated by exchange rather than by altruism. In other words, the gift and the counter-gift are a manifestation of enlightened self-interest, or of selfishness with foresight. To characterize them as reciprocal altruism is therefore misleading. Another important characteristic of gift exchanges as modelled by economists is that the reciprocal gesture typically takes on the same tangible form as the gift that triggered it. Sociologists and anthropologists, on the other hand, pay 
attention to symbolic as well as to material aspects of gift exchange relationships. As a consequence, there is the possibility that commodities are being traded against symbolic attributes such as social prestige and political power: a material gift, which never goes un-repaid, can thus be reciprocated, say, by a demonstration of loyalty, allegiance, subordination, devotion, etc...

An immediate implication is that gift exchanges can be asymmetrical, taking place between persons endowed with different wealth, rank or social status. In fact, as we have learned from the works of many anthropologists, more particularly Malinowski (1922), Mauss (1925), Polanyi (1944, 1968), Belshaw (1965), Sahlins (1960, 1974), Levi-Strauss (1969), and Bourdieu (1990), the whole point of the game may precisely consist for the dominant party of making sure that the tangible benefits or services that he renders (including insurance against the risk of hunger) can never be (fully) repaid. Being in his debt on the material level, the donee finds himself compelled to return the favour on another level, in ways that influence the donor's rank or status. Subordination is created and perpetuated because the obligation to reciprocate, which is a burden, cannot be relieved by means of a return gift equivalent to the initial gift (Offer, 1997: 455). Upon this reading, social prestige and political power originate in asymmetric gift exchanges.

In interactions where an agent (the donee or beneficiary) occupies an inferior rank or position vis-à-vis the other agent (the donor or benefactor), the former is likely to experience a feeling of social shame or, to speak more generally, to incur some kind of cost of subordination. This aversive emotion of shame is actually 
the reverse side of the prestige or power afforded by the dominating party who is also the gift-giver. Therefore, in analyzing political power or social status relationships in traditional contexts characterized by face-to-face (asymmetrical) relationships, these two mirroring components of utility, one positive and the other negative, need to be taken into account simultaneously.

So far, economists have made only a few attempts to model social prestige and social shame simultaneously, and all these attempts are quite recent (Hollnder, 1990; Van de Ven, 2002; Gaspart and Seki, 2003; Brennan and Pettit, 2005; Platteau and Seki, 2007). The present paper follows up these efforts, since it aims at a better understanding of the conditions under which unequal rank or power positions may get permanently established through asymmetric gift exchange when a gift brings pride to the donor and shame to the donee. It is noteworthy that the framework of patronage relations in which the party benefiting from a transfer accepts a low status and the accompanying loss of esteem (and freedom) can also be applied to international relations between aid-giving and aid-receiving countries, from where power considerations are rarely absent.

The structure of the paper is as follows. Section 2 further motivates the analysis proposed by briefly reviewing two types of relevant literature. First, attention is directed to the works of social scientists, anthropologists in particular, that vindicate our approach to power and status ranking. Thereafter, the rare attempts by economists to model social esteem and shame in a gift exchange framework are described and compared to the present endeavour. In Section 3, we present the basic assumptions underlying our model, with a special empha- 
sis on the features of the social esteem function, and we derive and discuss the equilibrium values of effort levels and transfer amounts. Since our main purpose is to discover how various dimensions of heterogeneity in the agents' characteristics are susceptible of giving rise to an asymmetric gift exchange equilibrium, the agents are allowed to have different effort productivities (owing to different talents or different endowments in physical or human capital), different costs of effort, and different sensitivities to social esteem and shame.

We are then able, in Section 4, to analyze the conditions under which one party will prefer to make a transfer and the other party will prefer to accept it, compared to a situation of autarky. We find that an asymmetric gift exchange equilibrium can occur only if the importance attached to social shame by a recipient is smaller than that attached to social esteem by a donor. Moreover, the likelihood of asymmetric gift exchange increases with the weight put on social esteem or power by the donor. Regarding the conditions related to productivity levels (or effort costs), we show that, depending on the configurations of the esteem coefficients of the two parties, the recipient's productivity may take on a rather wide range of values in the domain of feasibility of asymmetric gift exchange. Contrary to a commonly prevailing view, it is even possible, as shown in Section 5, that his productivity be identical to that of the donor. The conclusive section, Section 6, summarizes our main findings and discusses an interesting application to the sphere of international relations. 


\section{Power or status as asymmetric gift exchanges}

To explain power or status differentiation in terms of asymmetric gift exchange essentially means that the would-be dominant party tries to involve other members of the community in debt relationships. As a matter of fact, by accepting a gift, the donee manifests his readiness to play the role of the 'grateful recipient' (Schwartz 1967: 6). Thereby, he becomes an inferior and a subordinate, implying that he accepts the orders of the giver and complies with his wishes, thus rewarding him 'with power over himself as an inducement for furnishing the needed help' (Homans 1961: 319; Blau 1964: 21). In a like manner, Wintrobe (1998) considers that 'through the use of gifts, a donor, whether selfish or altruistic, can obtain power over recipients and induce their cooperation toward his or her own objectives' (p. 95).

Patronage relationships in the village societies of many developing countries seem to be grounded in such unequal exchange mechanisms, as attested by the frequent characterization of local patrons as 'Big Men' and the importance of symbolic exchanges of personal favours and obligations in this context (Polanyi, 1944, 1968; Pitt-Rivers, 1954; Belshaw, 1965; Epstein, 1968; Levi-Strauss, 1969; Breman, 1974; Scott, 1976; Bourdieu, 1990; Alexander, 1982; Platteau, 1995a). There are actually two different models of patronage and chieftaincy according to whether the making of regular tangible gifts by the dominant party is an obligation inherent in his power position, which is pre-established, or a means used toward creating the hierarchical order itself (Sahlins 1963; Finney 1972). The second situation, in which gift-making is the outcome of a strategic decision 
by a willing power-holder, is of more direct interest to the economist. In this more relevant case, gift exchange is a means by which the relations of domination and control are established. In the words of Mauss, 'the person who cannot return a loan loses his rank and even his status of a free man', which tends to happen in lineage-based economies where there is an unstable clan hierarchy changeable from time to time (Mauss, 1925: p.42; p.97, fn. 79; Gregory, 1982: p.20).

When considering the emergence of asymmetric power or status relationships in traditional social contexts, it is clearly important to bear in mind the cost of subordination for the subject person or the client. There is actually solid psychological evidence not only that pride is a rewarding emotion commonly elicited by dominance, but also that shame is an aversive emotion typically elicited by subordinance, and negatively correlated with self-esteem (Fessler 2001; see also Frank 1985, 1989; Robben and Verhallen 1994; Offer 1997; Clark and Oswald, 1998; Gächter and Fehr 1999) ${ }^{1}$.

In Fessler's framework, there is no compensation (e.g., a gift) for social shame, and this is why people subject to this painful emotion tend to withdraw from interaction and, if it is not possible, they turn aggressive and attack the dominating individual in the hope of inverting the dominance relationship (Fessler 2001: 199-200). His analysis indirectly confirms Bourdieu's proposition that, in societies pervaded by highly personalized face-to-face relationships, and

\footnotetext{
${ }^{1}$ As pointed out a long time ago by David Hume (1888), in the same way that 'anger and hatred bestow a new force on all our thoughts and actions', it appears that, 'humility and shame deject and discourage us'(Book II, Section X, p.391).
} 
where there are no institutionalized rules governing access to, and reproduction of, power, power cannot be established in a direct and brutal manner lest the whole fabric of the society should be undermined and power prove unsustainable. In such circumstances where domination can only be exerted overtly, in its elementary form (from person to person), the practice of asymmetric gifts made 'under the veil of enchanted relations' epitomized by parent-children relationships, is the best method available to would-be patrons or chiefs concerned with making their authority accepted at a reasonable cost for the subject people:

So long as overt violence... is liable to provoke either a violent riposte or the flight of the victim -that is, in both cases, for lack of any legal recourse, the destruction of the very relationship that was to be exploited- symbolic violence, gentle, invisible violence, unrecognized as such, chosen as much as undergone, that of trust, obligation, personal loyalty, gifts, debts, presents itself as the most economical mode of domination because it best corresponds to the economy of the system (Bourdieu 1990: 127).

Power is established by manifesting one's superiority through the distribution of gifts to would-be supporters. These gifts help build up 'a capital of obligations and debts that will be repaid in the form of homage, respect, loyalty and, when the occasion arises, work and services'. They form 'a symbolic capital' that secures recognition of power: inasmuch as common people are obliged to the emerging leader-benefactor without feeling humiliated, they are ready to pledge allegiance to him and accept their lower position. Gift-making 
thus appears as a sort of 'demonstrative expenditure', 'a kind of legitimizing self-affirmation through which power makes itself known and recognized'. It can therefore be said that "this power awards itself a rudimentary form of institutionalization by officializing itself' (Bourdieu 1990: 125, 131). If gifts are repeated more or less regularly, power can be durably established in this political war for rank, distinction and pre-eminence ${ }^{2}$.

We can now shift our attention to the most relevant economic literature. On some occasions, when discussing patron-client relationships, economists have allowed for the possibility that part of the benefits earned by the patrons are of the symbolic type. This enables them to explain why, for example, patrons may choose to enter and stay into a pooling arrangement from which they do not apparently draw benefits comparable to those obtainable under autarky (Fafchamps 1992; Platteau 1995b). In these works, however, the social shame experienced by the dominated party (the client) while receiving gifts is overlooked.

In a pioneer paper, Hollnder (1990) considers the possibility of both positive and negative social approval in the context of a public good provision problem. In this setup, agents enjoy the gratitude and sympathy of others if they happen to have contributed an above-average effort to the production of the public good.

\footnotetext{
${ }^{2}$ By contrast: 'In place of the relationships between persons indissociable from the functions they fulfil, which they can perpetuate only at direct personal cost, institutionalization sets up strictly established, legally guaranteed relations between recognized positions, defined by their rank in a relatively autonomous space, distinct from and independent of their actual and potential occupants...' (Bourdieu 1990: 131).
} 
In the converse case where their contribution is comparatively small, they suffer from a negative approval effect. On the other hand, Gaspart and Seki (2003) and Platteau and Seki (2007) have explicitly modelled the two-way effects of unilateral transfers on self-esteem in the specific context of an income-pooling scheme with agents of different abilities exploiting a common property resource. While the former attempt to discover the conditions related to the operation of the esteem factor under which the effort equilibrium levels obtained under the scheme are identical to the first-best levels (bear in mind that, owing to the presence of externalities, decentralized effort decisions cannot achieve first-best efficiency in the absence of social esteem), the latter examine the conditions under which the agents would prefer to pool incomes under an equal division rule, and experience the associated esteem effects, to remaining autarkic and avoiding such effects. It is noteworthy that, in the second endeavour, but not in the first, sensitivities to esteem are assumed to be identical between agents. One of the central interests of Van de Ven (2002), on the other hand, is to explain the existence of reciprocal gifts. Instead of looking for the kind of motivations commonly used in the economic literature (see supra, Section 1), he explains gift-giving by a demand for social approval and conceives reciprocal gift-giving as an instrument in the race for status. However, he does not characterize the associated equilibrium and, therefore, we can never be certain that a gift made will be accepted in the assumed presence of social shame.

In contrast, the present attempt does not aim at explaining reciprocal gifts since we want to understand states characterized by permanent power and status 
asymmetries. It is true that such states could be viewed as the end outcomes of a series of rounds in which the agents make gifts and counter-gifts. However, we have chosen not to follow this path in order to concentrate our attention on the issue of feasibility of asymmetric states and the precise conditions under which they may obtain ${ }^{3}$.

Compared to Platteau and Seki (2007), we want to build a more general framework in the three following senses. First, the amount of the transfer is endogenized rather than being fixed by a predetermined rule. Second, the sensitivities to social esteem and shame are left free to vary between the agents. And, third, the social esteem function is not restricted to a linear form. Unlike what is done in Gaspart and Seki (2003), we are not interested in comparing the equilibrium obtained under a transfer scheme with the first-best efficient equilibrium, but in comparing it with autarky. In the situation which we are going to examine, there are no production externalities and, therefore, the question as to whether social esteem considerations can possibly mitigate the incentive problem typical of common property exploitation, does not arise.

\footnotetext{
${ }^{3}$ In fact, Van de Ven has not proposed a dynamic game that really depicts the race for status. Essentially, what he does is to depict the reaction functions of the two agents in terms of the gifts (or counter-gifts) that they want to make. The equilibria as such are not derived and characterized, however. Moreover, since there are gifts and counter-gifts, the author conceives social approval as a net amount obtained by subtracting the negative social esteem accompanying the receipt of gifts from the positive esteem associated with the making of gifts to the partner. The psychological foundations of this sort of esteem arithmetic are far from obvious, however
} 


\section{The setup of the model and first results}

\subsection{The setup of the model}

Two individuals choose their optimal effort level which is the unique and costly input in the production of a consumption good. The agents are endowed with different productivities, and their disutility of effort may also differ. The production function is atomistic (no production pooling is possible across the two agents) and linear in the effort invested, and the effort cost function is convex. Each agent derives a positive utility from the total amount produced and consumed, and a disutility from working. We assume that only one agent has the ability to make a gift that the other agent can either accept or refuse. Part of the effort applied by the donor is allocated to producing his own consumption good, while the remaining part is allocated to producing the gift. When a gift is accepted, the donor, who has chosen the optimal gift-producing effort, achieves a higher social status or prestige because he contributes to the recipient's material welfare. As for the latter, although he enjoys an increase in utility arising from the additional consumption allowed by the gift, he also suffers from a loss of status or esteem that negatively affects his utility. Yet, he is only a potential recipient since he could reject the gift. If he does we are back to a situation of no interaction between the agents who, being autarkic, derive utility from consumption of own production alone.

We now turn to the specification of the social esteem function. Two possible approaches that we want to consider are the following. First, there is the con- 
ventional approach according to which the amount of social esteem or shame experienced by the agent is proportional to the absolute value of the gift given or received. In the second approach, social esteem or shame is a function of the share of the gift in the total consumption of the recipient. We believe that this approach is more appropriate to describe situations in which power is at stake. Indeed, the larger the share of the gift in the donee's consumption, the higher the degree of his dependence on the donor, and the stronger the power afforded by the latter. Upon this understanding, even a gift of small (absolute) value might give rise to a lot of power if it constitutes a substantial portion of the recipient's consumption.

This being said, the first approach is worth examining since it is actually devoid of any element of strategic interactions (Indeed, the effort chosen by the recipient does not affect the esteem value of the gift for the donor). It, therefore, leads to a rather straightforward result which will be usefully compared to the more complex results obtained under the second approach.

Let us write a utility function that has three components: a first component which reflects the direct effect of own effort (assumed to be linear); a second component which reflects the cost of total effort (assumed to have a convex form); and a third component, measuring the influence of esteem, that is a (non-linear) function of the absolute amount of the gift's transfer. We thus have the following utility functions for the gift maker (agent $i$ ) and the recipient (agent $j)$ : 


$$
\begin{aligned}
& U_{i}\left(x_{i}, t_{i}, x_{j}\right)=\alpha_{i} x_{i}-\beta_{i}\left(x_{i}+t_{i}\right)^{2}+\underline{u}_{g} e_{i}\left(\alpha_{i} t_{i}\right)^{\gamma} \\
& U_{j}\left(x_{j}, t_{i}\right)=\alpha_{j} x_{j}-\beta_{j} x_{j}^{2}+\underline{u}_{g}\left\{\alpha_{i} t_{i}-e_{j}\left(\alpha_{i} t_{i}\right)^{\gamma}\right\}
\end{aligned}
$$

where the two constants, $e_{i}$ and $e_{j}$, stand for the non-negative esteem parameters, the $\alpha$ parameters are the agents' respective marginal productivities of effort, the $\beta$ 's measure the costs of effort, and $\underline{u}_{g}$ is an indicator function equal to the unit value when the recipient accepts the gift. In the above specification, the total effort chosen by agent $i$ is allocated between production of his own consumption good, $x_{i}$, and production of a gift for $j, t_{i}$. Therefore $\alpha_{i} x_{i}$ measures his consumption, and $\alpha_{i} t_{i}$ corresponds to the amount of the gift. As for the parameter $\gamma$, it determines whether the esteem component of the utility function is concave, convex, or linear.

We assume that the game played is sequential: the recipient first decides his work effort knowing that the gift-giver will then choose both his effort for own consumption and the size of the gift. This two-stage game can thus be solved backwardly, starting with the gift maker's maximization problem.

For the gift-maker, the optimal levels of own consumption and the gift are obtained by maximizing his utility function with respect to $x_{i}$ and $t_{i}$. The resulting equilibrium values are, respectively:

$$
\alpha_{i} t_{i}=\left(\gamma e_{i}\right)^{\frac{1}{1-\gamma}}
$$




$$
\alpha_{i} x_{i}=\frac{\alpha_{i}^{2}}{\beta_{i}}-\alpha_{i} t_{i}
$$

Likewise, the optimal level of effort of the recipient is obtained by maximizing his utility function with respect to $x_{j}$, yielding the following expression for his self-produced consumption:

$$
\alpha_{j} x_{j}=\frac{\alpha_{j}^{2}}{2 \beta_{j}}
$$

It is noteworthy that this value is independent of the amount of the gift. In fact, it is strictly identical to the value obtained under autarky (which is derived by maximizing $j$ 's utility function from which the esteem component has been removed). The next step is to check whether the gift is acceptable to player $j$, the potential recipient. In fact, since self-produced consumption of player $j$ is independent of the value of the gift, the gift will be accepted only if its intrinsic utility is greater than the loss of status involved. Comparing $j$ 's utility in the presence of the gift with his utility under autarky, and using (3), we obtain the following condition:

$$
\alpha_{i} t_{i} \geq e_{j}\left(\alpha_{i} t_{i}\right)^{\gamma} \Rightarrow\left(\gamma e_{i}\right) \geq e_{j}
$$

Clearly, when status is influenced by the absolute amount of the gift, and when the esteem function is concave or linear $(\gamma \leq 1)$, the importance attached to social shame by the donee must not exceed that attached to social esteem by the donor if the former is to accept the gift. And the stronger the concavity, the more stringent the condition. 
Making the players' utility a function of the relative contribution of the donor's gift in the donee's total consumption has the effect of enriching our framework in the two following senses. First, the recipient strategically selects his work effort, and, second, the impact of a gift on the social esteem component of the utility of both agents is no more independent of the level of the recipient's production. As a first attempt, we have used the logarithmic form to describe the influence of social esteem on the two players' utilities. Unfortunately, if this specification is rather easy to handle, it leads to results that do not have the general character that we aim at. In particular, as shown in Appendix (A.1), the equilibrium level of effort of the recipient does not depend on the esteem coefficient of the donor, nor on the productivity of either agent.

We have, therefore, chosen to use a less elegant but more fecund specification which we write as follows, assuming as before that player $i$ is the gift-maker:

$$
\begin{array}{r}
U_{i}\left(x_{i}, t_{i}, x_{j}\right)=\alpha_{i} x_{i}-\beta_{i}\left(x_{i}+t_{i}\right)^{2}+\underline{u}_{g}\left\{e_{i}\left[\left(\frac{\alpha_{j} x_{j}+\alpha_{i} t_{i}}{\alpha_{j} x_{j}}\right)^{\gamma}-1\right]\right\} \\
U_{j}\left(x_{j}, t_{i}\right)=\alpha_{j} x_{j}-\beta_{j} x_{j}^{2}+\underline{u}_{g}\left\{\alpha_{i} t_{i}-e_{j}\left[\left(\frac{\alpha_{j} x_{j}+\alpha_{i} t_{i}}{\alpha_{j} x_{j}}\right)^{\gamma}-1\right]\right\}
\end{array}
$$

For the sake of computational convenience, we have written the argument of the esteem component of the utility function not as the ratio of the gift to $j$ 's total consumption, but as the percentage by which the gift allows $j$ to increase his consumption ${ }^{4}$.

As in the previous specification, the parameter $\gamma$ determines the shape of

\footnotetext{
${ }^{4}$ When we use the ratio of the gift to $j$ 's total consumption, denoted by $F\left(x_{i}, t_{i}, x_{j}\right)$,
} as argument of the esteem function, the optimizing procedure leads to complex expressions 
the esteem function. This is evident from Figure (1), where the amount of social esteem or shame experienced by player $i$, which is measured along the vertical axis, varies according to the amount of the gift made or received by him, which is measured along the horizontal axis. Three different curves have been drawn depending on the value of $\gamma$, all under the assumption that the effort of the giftreceiver is fixed. In the North-East quadrant, $i$ makes a gift to $j$, and enjoys social prestige accordingly. By contrast, in the South-West quadrant, it is now $j$ who makes a gift to $i$, who suffers from social shame. It is debatable which shape is more convenient to describe a phenomenon as complex as social esteem. Yet, for our purpose, concavity appears to offer a better description of human emotions $(\gamma<1)$. The initial units of a gift received cause the greatest pain in as much as they create a dependence on the donor's goodwill. Additional units have a diminished impact since the donee has become accustomed to his dependent position. By analogy, this holds true for the donor as well: his social prestige increases with his apparent generosity, but mostly when his relative contribution to the donee's consumption is low.

For the sake of completeness, however, we will check how the alternative assumptions of a convex $(\gamma>1)$, or a linear $(\gamma=1)$, esteem function affect our results.

(multiple-root polynomials) that are very hard to handle analytically. We have, therefore, opted for the specification given in the text, that we denote by $E\left(x_{i}, t_{i}, x_{j}\right)$. The good news is that this function behaves in a fairly similar fashion to $F($.$) . Indeed, if we denote by E_{x_{j}^{n}}($.$) its$ $n^{t h}$-order derivative with respect to $x_{j}$, we are able to show that $\operatorname{sign}\left[F_{x_{j}}().\right]=\operatorname{sign}\left[E_{x_{j}}().\right]$, $\operatorname{sign}\left[F_{x_{j}^{2}}().\right]=\operatorname{sign}\left[E_{x_{j}^{2}}().\right], \operatorname{sign}\left[F_{t_{i}}().\right]=\operatorname{sign}\left[E_{t_{i}}().\right]$, and $\operatorname{sign}\left[F_{t_{i}^{2}}().\right]=\operatorname{sign}\left[E_{t_{i}^{2}}().\right]$. 


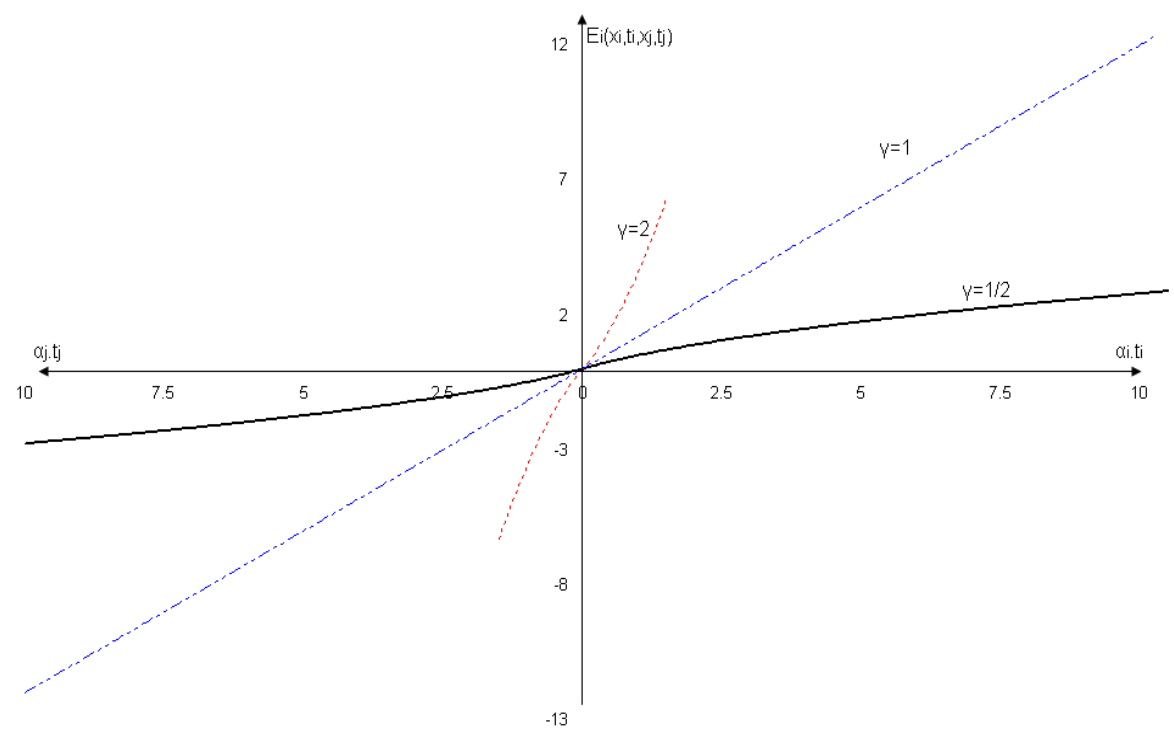

Figure 1: Esteem Component of agent $i$ 's utility function

We are now ready to solve the two-stage game of gift-and-esteem exchange when players strategically interact.

\subsection{First results}

The maximization problem of player $i$, the potential gift-maker, when the gift is both made and accepted, is given by:

$$
\begin{aligned}
& \operatorname{Max}_{x_{i}, t_{i}}\left\{\alpha_{i} x_{i}-\beta_{i}\left(x_{i}+t_{i}\right)^{2}+e_{i}\left(\left(\frac{\alpha_{j} x_{j}+\alpha_{i} t_{i}}{\alpha_{j} x_{j}}\right)^{\gamma}-1\right)\right\} \\
& \text { s.t. } t_{i} \geq 0 \\
& x_{i} \geq 0
\end{aligned}
$$

Combining the two first-order conditions, and assuming that the two con- 
straints are not binding, we obtain:

$$
\begin{gathered}
x_{i}=\frac{\alpha_{i}}{2 \beta_{i}}-t_{i} \\
\Rightarrow t_{i}=\frac{\alpha_{j} x_{j}}{\alpha_{i}}\left(\left(\frac{\alpha_{j} x_{j}}{e_{i} \gamma}\right)^{\frac{1}{\gamma-1}}-1\right)
\end{gathered}
$$

Conditions (9) and (10) can then be re-written as:

$$
\begin{aligned}
& \frac{\alpha_{i}}{2 \beta_{i}} \geq t_{i} \Rightarrow \frac{\alpha_{i}^{2}}{2 \beta_{i}} \geq\left(\frac{\left(\alpha_{j} x_{j}\right)^{\gamma}}{e_{i} \gamma}\right)^{\frac{1}{\gamma-1}}-\alpha_{j} x_{j} \\
& \frac{\alpha_{j} x_{j}}{e_{i} \gamma} \geq 1 \quad \text { if } \gamma>1 \\
& \frac{\alpha_{j} x_{j}}{e_{i} \gamma} \leq 1 \quad \text { if } \gamma<1
\end{aligned}
$$

Starting with condition (10'), it is evident that, when the social esteem function is concave, player $i$ will agree to make a gift to player $j$ only if the latter's self-produced consumption is small enough compared to the importance attached to social esteem by the former. The opposite condition obtains when the esteem function is convex. This is an intuitive result. Indeed, when social esteem rises quickly at low levels of the recipient's dependence on the donor, the donor will choose to compel the recipient to exert much effort, with the consequence that the latter's degree of dependence remains moderate. On the other hand, as condition (9') shows, player $i$ will make a positive effort towards his own consumption $\left(x_{i}>0\right)$ only if he is productive enough (high $\left.\alpha_{i}\right)$ and/or the cost of his effort is relatively low, and/or the importance attached to social esteem by him is not too high (bear in mind that $\gamma<1$ ). If it is too high, indeed, his effort would be totally absorbed in the production of the gift.

Let us now turn to the problem of the potential gift-receiver, player $j$. This is done by substituting the optimal value of the gift given by equation (12) into 
j's utility function depicted by (7).

The optimal level of effort put in by $j$ is then equal to

$$
\Rightarrow x_{j}^{o}=\left[\left(\frac{\alpha_{j}}{e_{i}}\right)^{\frac{\gamma}{\gamma-1}} \frac{\left(e_{i} \gamma-e_{j}\right)}{(\gamma-1) \gamma^{\frac{1}{\gamma-1}} 2 \beta_{j}}\right]^{\frac{\gamma-1}{\gamma-2}}
$$

Under the hypothesis, to be verified later, that $j$ accepts the gift, and keeping in mind that $\gamma<1$, we see that $j$ 's equilibrium effort is positive if and only if $e_{j}>e_{i} \gamma$. Shall this inequality not hold, since $x_{j}$ is constrained to be nonnegative, it will be nil ( $j$ is a parasite), implying that no gift is made by $i$ (as is evident from condition (12)). In our model, therefore, parasitism cannot be an equilibrium. From the above condition, $e_{j}>\gamma e_{i}$, it is evident that, in order that the gift is made, the importance attached to social shame by $j$ (measured by the esteem coefficient $e_{j}$ ) should not be too small compared to the importance attached to social prestige by $i$ (measured by the esteem coefficient $e_{i}$ ). Yet, the stronger the concavity of the social esteem function (the lower the value of $\gamma)$, the less stringent this condition.

Another conclusion follows from the above equations: the esteem coefficient of agent $i$ must neither be too large, nor too small if a gift is to take place from him to agent $j$. If it is too small, $t_{i}$ would equal zero according to (10) and (12), and, if it is too large (compared to $e_{j}$ ), condition $e_{j}>e_{i} \gamma$ would be violated.

At this juncture, it is useful to make a pause to refine our interpretation of the equilibrium conditions. To make things clearer, we assume that $\gamma=1 / 2$. First consider the viewpoint of agent $i$. Since the marginal cost of production is identical whether the effort is directed towards own consumption or towards 
gift-giving, we need not be concerned with this trade-off: at equilibrium the marginal benefits in both activities (own consumption and transfer) ought to be identical and total effort should be such that they both equal the marginal cost of production. Raising $t_{i}$ by one unit implies a decrease of $\alpha_{i}$ in the amount of own consumption: the marginal opportunity cost of increasing $t_{i}$ is thus the productivity of the gift-giver's effort. As for the marginal benefit of the same, it is measured in terms of a gain of esteem/status. Derived from (6), it is measured by:

$$
\frac{e_{i} \alpha_{i}}{2\left(\alpha_{j} x_{j}\right)^{1 / 2}\left(\alpha_{j} x_{j}+\alpha_{i} t_{i}\right)^{1 / 2}}>0
$$

This expression is positive but decreasing in $\alpha_{i} t_{i}$, since the esteem function is concave. Moreover, larger values of $\alpha_{j} x_{j}$ push the marginal benefit of giftgiving downwards. Denoting by $E_{i}$ the esteem component of the utility function of player $i$, we have that

$$
\frac{\partial E_{i}}{\partial t_{i}}>0 \quad, \quad \frac{\partial E_{i}^{2}}{\partial^{2} t_{i}}<0 \quad, \quad \frac{\partial E_{i}^{2}}{\partial t_{i} \partial x_{j}}<0
$$

Clearly, a higher amount of effort on the part of the beneficiary causes the marginal value of gift-giving (as measured by $\partial E_{i} / \partial t_{i}$ ) to diminish. As a result, in order to restore the equality between the marginal benefit of own production $\left(\alpha_{i}\right)$ and the marginal benefit of esteem $\left(\partial E_{i} / \partial t_{i}\right)$, the donor reduces the amount of his gift. This is the meaning behind the comparative static result $\partial t_{i} / \partial x_{j}<0$ obtained from $(12)^{5}$.

\footnotetext{
${ }^{5} \mathrm{We}$, indeed, have that $\frac{\partial t_{i}}{\partial x_{j}}=-\frac{\alpha_{j}}{\alpha_{i}}\left[1+\left(\frac{e_{i}}{2 \alpha_{j} x_{j}}\right)^{2}\right]$.
} 
Keeping in mind the logic behind the donor's decision, we may turn to the donee's problem. After plugging the optimal value of the gift chosen by player $i$ in his utility function, we obtain for $\gamma=1 / 2$ :

$$
U_{j}=\alpha_{j} x_{j}-\beta_{j} x_{j}^{2}+\frac{e_{i}^{2}}{4 \alpha_{j} x_{j}}-\alpha_{j} x_{j}-\frac{e_{j} e_{i}}{2 \alpha_{j} x_{j}}+e_{j}
$$

Taking the first order derivative w.r.t. $x_{j}$, we get:

$$
\partial U_{j} / \partial x_{j}=\alpha_{j}-2 \beta_{j} x_{j}-\left(\frac{e_{i}^{2}}{4 \alpha_{j} x_{j}^{2}}+\alpha_{j}\right)+\frac{e_{j} e_{i}}{2 \alpha_{j} x_{j}^{2}}
$$

The marginal benefit of $x_{j}$ is the sum of the first and the fourth terms in the above expression, that is, respectively, the marginal increase in self-produced consumption, and a decrease in the loss of social esteem. Regarding the latter, remember that, when $x_{j}$ is raised, $i$ responds by diminishing the amount of the gift, which eventually leads to a lower dependence ratio, $\frac{\alpha_{j} x_{j}+\alpha_{i} t_{i}}{\alpha_{j} x_{j}}$.

The marginal cost, on the other hand, is the sum of the marginal cost of effort (the second term) and the reduced amount of the gift (the third term). It is evident from this third term that the forsaken amount of the gift is a negative function of $\alpha_{j} x_{j}$.

Equating $\partial U_{j} / \partial x_{j}$ to zero, the equilibrium amount of own production by agent $j$ is:

$$
\alpha_{j} x_{j}=\frac{1}{2}\left(\frac{\alpha_{j}^{2}}{\beta_{j}} e_{i}^{2}\left(2 \frac{e_{j}}{e_{i}}-1\right)\right)^{1 / 3}
$$

It is immediately obvious that, when the equilibrium amount of effort of agent $j$ is positive, which implies that $e_{j} \geq e_{i} / 2$, the output produced by him increases as his productivity is higher (or his cost of effort lower), and as his 
esteem coefficient is larger:

$$
\frac{\partial \alpha_{j} x_{j}}{\partial \alpha_{j}}>0, \frac{\partial \alpha_{j} x_{j}}{\partial \beta_{j}}<0, \frac{\partial \alpha_{j} x_{j}}{\partial e_{j}}>0
$$

The first two results are standard, and the third one reflects the fact that, when agent $j$ is more sensitive to social shame, he responds by increasing his level of output so as to mitigate the social shame effect. As for the effect of a change in agent $i$ 's esteem coefficient on agent $j$ 's output (and effort), it is indeterminate. However, we will show at a later stage that this indeterminacy can be lifted once we introduce further restrictions corresponding to the domain of feasibility of the asymmetric gift exchange. It is straightforward that the partial derivatives of $j$ 's equilibrium amount of effort with respect to $\beta_{j}$ and $e_{j}$ have the same signs as those shown above. Yet, the effect of a change in $\alpha_{j}$ on $x_{j}$ is negative, implying that productivity and effort are substitutes in the case of the gift beneficiary. This outcome contrasts with that obtained for the gift-maker: as can be seen from equation (11), when agent $i$ 's productivity increases, his total effort (and output) also increase.

The above discussion is based on the assumption that the social esteem function is concave. When this function is convex or linear, it appears that interior solutions can no more be obtained. In the case of convexity, player $j$ will either choose to produce no effort at all, or to apply an infinite amount of effort. In the former case, player $i$ will make no gift, while, in the latter case, he will produce the maximum amount of gift compatible with his productive ability. In the case of linearity, irrespective of the amount of effort applied by player $j$, player $i$ will either decide to make no gift, or to produce the maximum 
amount compatible with his productive ability (hence the fact that the case $\gamma=1$ does not figure out in condition $\left.\left(10^{\prime}\right)\right)$.

A formal proof of these results is provided in Appendix A.2.

\section{Conditions for mutual agreement on a gift}

We may now embark upon the central task of determining whether player $j$ will actually accept the gift proposed by player $i$. To answer this question, we compare the utility that player $j$ would gain by accepting the gift with his stand alone utility: $j$ is induced to accept the gift if the former exceeds the latter. Bearing equation (5) in mind, this condition is the following:

$$
U_{j}^{o}=\alpha_{j} x_{j}^{o}+\alpha_{i} t_{i}^{o}-\beta_{j} x_{j}^{o 2}-e_{j}\left(\left(\frac{\alpha_{j} x_{j}^{o}+\alpha_{i} t_{i}^{o}}{\alpha_{j} x_{j}^{o}}\right)^{\gamma}-1\right) \geq \frac{\alpha_{j}^{2}}{4 \beta_{j}}=U_{j}^{b}
$$

Which, using the results derived up to now, is re-written as:

$$
e_{j} \geq \frac{\alpha_{j}^{2}}{4 \beta_{j}}+\left(e_{j}-e_{i} \gamma\right)\left(\frac{\alpha_{j} x_{j}^{o}}{e_{i} \gamma}\right)^{\frac{\gamma}{\gamma-1}}+\beta_{j} x_{j}^{o 2}
$$

or, using the value of $x_{j}^{o}$,

$$
e_{j} \geq \frac{\alpha_{j}^{2}}{4 \beta_{j}}+\left[\frac{\alpha_{j}^{2}\left(e_{j}-\gamma e_{i}\right)^{\frac{2(\gamma-1)}{\gamma}}}{(1-\gamma) 2 \beta_{j} \gamma e_{i}^{2}}\right]^{\frac{\gamma}{\gamma-2}}+\beta_{j}\left[\frac{\alpha_{j}^{\frac{\gamma}{\gamma-1}}\left(e_{j}-\gamma e_{i}\right)}{(1-\gamma) 2 \beta_{j}\left(\gamma e_{i}^{\gamma}\right)^{\frac{1}{\gamma-1}}}\right]^{\frac{2(\gamma-1)}{\gamma-2}}
$$

Unfortunately, the above condition is analytically intractable. To simplify matters, we shall set $\gamma=1 / 2$, and try to elucidate under what conditions a patron-client relation is likely to emerge and determine the characteristics of the would-be patron and the would-be client. Condition (15) thus becomes:

$$
e_{j}-\frac{\alpha_{j}^{2}}{4 \beta_{j}}-\frac{3}{4}\left(\frac{e_{i}^{2}\left(2 e_{j}-e_{i}\right)^{2} \beta_{j}}{\alpha_{j}^{2}}\right)^{1 / 3} \geq 0
$$


The stage is now set for an inquiry about the feasibility of a mutually profitable (asymmetrical) gift exchange in the relevant domain of the esteem coefficients.

To begin with, let us write down the value of the gift potentially made by agent $i$ when the equilibrium effort level applied by player $j$ is taken into account. This is done by plugging equation (13) into equation (17). We thus obtain the following expression:

$$
\alpha_{i} t_{i}^{o}=\left[\frac{\alpha_{j}^{2}\left(\gamma e_{i}-e_{j}\right)}{(\gamma-1) 2 \beta_{j}\left(\gamma e_{i}^{\gamma}\right)^{\frac{1}{\gamma-1}}}\right]^{\frac{\gamma-1}{\gamma-2}} \times\left[\left[\frac{\alpha_{j}^{2}\left(\gamma e_{i}-e_{j}\right)}{(\gamma-1) 2 \beta_{j} \gamma e_{i}^{2}}\right]^{\frac{1}{\gamma-2}}-1\right]
$$

When $\gamma=1 / 2$, this expression will be positive if:

$$
\kappa \leq \frac{e_{i}}{2 X}+1 / 2
$$

where $\kappa$ is the ratio of esteem coefficients $\left(\kappa=e_{j} / e_{i}\right)$, and $X$ measures the (squared) productivity of player $j$ relative to his effort cost $\left(X=\alpha_{j}^{2} / \beta_{j}\right)$.

The interpretation of this condition is straightforward: a gift is more likely to be made by agent $i$ when (1) agent $i$ puts more weight on social esteem, (2) agent $j$ attaches lower importance on social esteem/shame, and (3) the productivity of agent $j$ is lower (or his effort cost higher).

For the potential gift made by agent $i$ to be acceptable by $j$, we know that condition (16) must be satisfied. With the above notations, it can be re-written in a form that is more simple, yet remains difficult to interpret:

$$
X^{1 / 3}\left(4 \kappa e_{i}-X\right) \geq 3 e_{i}^{4 / 3}(2 \kappa-1)^{2 / 3}
$$

Given the complexity of the condition obtained for the acceptability of the 
gift by $j$, we must resort to the simulation technique, at least as a first step, in order to highlight the critical factors that eventually determine the feasibility of an asymmetrical gift exchange. Towards that purpose, we use equations (18) and (19). The method followed consists of fixing $e_{i}$, and then varying the $X$ and $\kappa$ parameters to see when the above two conditions are satisfied.

In Figure (2), the dark-shaded area depicts the domain of $(X, \kappa)$ values within which the gift is accepted by agent $j$, assuming that $e_{i}=10$. This domain is made of two triangle-like areas, one of which is inverted, touching each other at their summits. The interpretation of these results is as follows. Looking at the lower triangle, it appears that, when the potential donee attaches more importance to social shame (higher values of $\kappa$ ), he is less likely to accept the gift, which is according to intuition. For a given, rather low value of $e_{j}$ $(\kappa<1), j$ 's inducement to accept the gift increases with his own productivity, yet only up to to a certain point beyond which his inducement starts to decrease. Ultimately, the gift is refused. Bear in mind that an increase in the productivity of agent $j$ implies that, all other things being equal, his degree of dependence on agent $i$ 's goodwill is lower and, therefore, the cost of a gift in terms of loss of esteem is smaller. Above a certain threshold, however, his productivity becomes so large that he prefers to remain autarkic.

Less obvious is the situation described by the upper, inverted, triangle. As the weight put on social shame increases above a certain threshold, which is in the neighbourhood of $1\left(e_{i}=e_{j}\right)$, the prospect of acceptance of the gift by agent $j$ improves provided that his effort productivity is moderately high, yet 


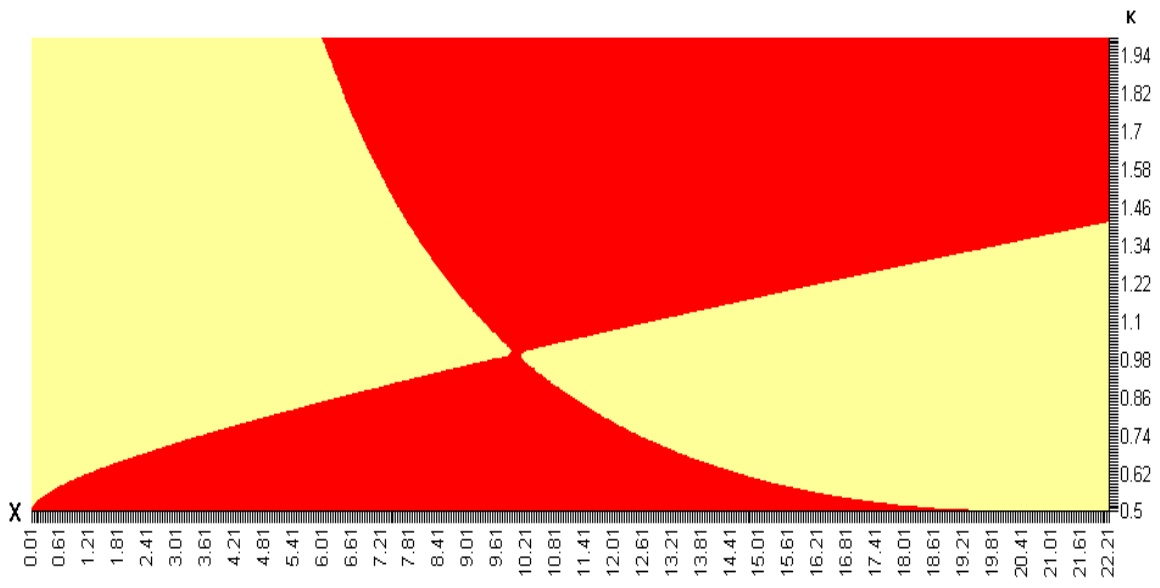

Figure 2: Gift acceptability condition $\left(e_{i}=10\right)$

not too high (or his cost of effort is moderately low, yet not too low). The idea is that, when shame weighs much on the utility of agent $j$, he tends to react to a gift by considerably increasing his own production, which necessitates that his productivity is large enough. Above a certain level of productivity, however, he prefers to avoid social shame altogether by refusing the gift and living in autarky.

Does the result depicted in Figure (2) depends on the value of the donor's esteem coefficient? To answer that question, we have drawn, in Figure (3), the domain of acceptability of the gift when the value of $e_{i}$ is reduced from 10 to 1 . It is immediately apparent that, if the shape of the domain is broadly similar, it has shifted leftwards and its size has been considerably reduced. With $e_{i}=1$, only low values of the recipient's productivity are susceptible of inducing him to accept the gift. The rationale is the following: when the recipient has a low 
income-earning capacity, a transfer of a given amount represents a larger share of his income which makes the gift more acceptable to him even though the gift is rather small (owing to the donor's low sensitivity to social esteem or power).

To sum up, a patron-client relationship is more likely to arise when the potential donor puts a greater weight on social esteem or power. This may imply that patronage has a more fertile ground to grow on if the group to which the donor and the recipient belong has a larger size. Indeed, as pointed out by Fessler (2001) on the basis of experimental psychological evidence, there is a positive relationship between the esteem coefficients and the number of witnesses: 'the intensity of Shame or Pride experienced is in part contingent on the audience present' (p.201). This is true, however, only if the number of witnesses belong to the reference group of the donors and donees: an agent can obtain positive or negative approval from people who know his behaviour only if the latter are able, in one way or another, to communicate their feelings to him (Hollnder, 1990 p.1159).

Let us now look at the condition for gift making by agent $i$ (condition (18)). The corresponding domain of feasibility is depicted by the dark shaded area in Figure (4). When the two feasibility areas are superimposed on each other, we obtain Figure (5). A striking feature is that the upper triangle appearing in Figures (2) and (3), which describe the condition for gift acceptability by agent $j$, has vanished. As has been pointed out earlier, above a certain value of $e_{j}$, agent $j$ starts putting in a lot of effort to mitigate the effect of social shame and, as a consequence, the cost of making a gift for agent $i$ increases (bear in 


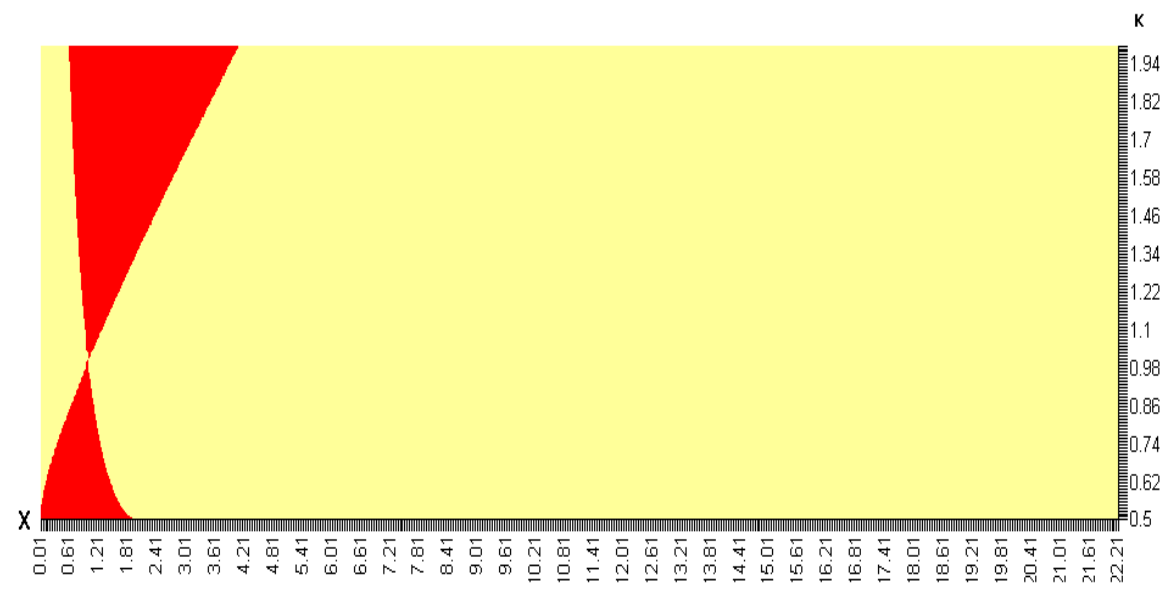

Figure 3: Gift acceptability condition $\left(e_{i}=1\right)$

mind that the argument in the esteem function is not the absolute value of the gift, but the share it represents in $j$ 's consumption).

The salient result emerging from Figures (2) and (3) is that there exists a critical value of $\kappa$, equal to one, above which the feasibility domain is empty. In words, asymmetric gift exchanges are infeasible when the weight attached to shame by the recipient exceeds the weight attached to social esteem or prestige by the gift-maker ${ }^{6}$.

This important result which we had already obtained under the first specification of the social esteem function (see supra, Section 3.1), can be proved formally.

\footnotetext{
${ }^{6}$ If we believe David Hume for whom 'we are more elevated with the view of one below us, than mortified with the presence of one above us' (Hume, 1888: Book II, Section X, 390), such a circumstance is not likely to arise.
} 


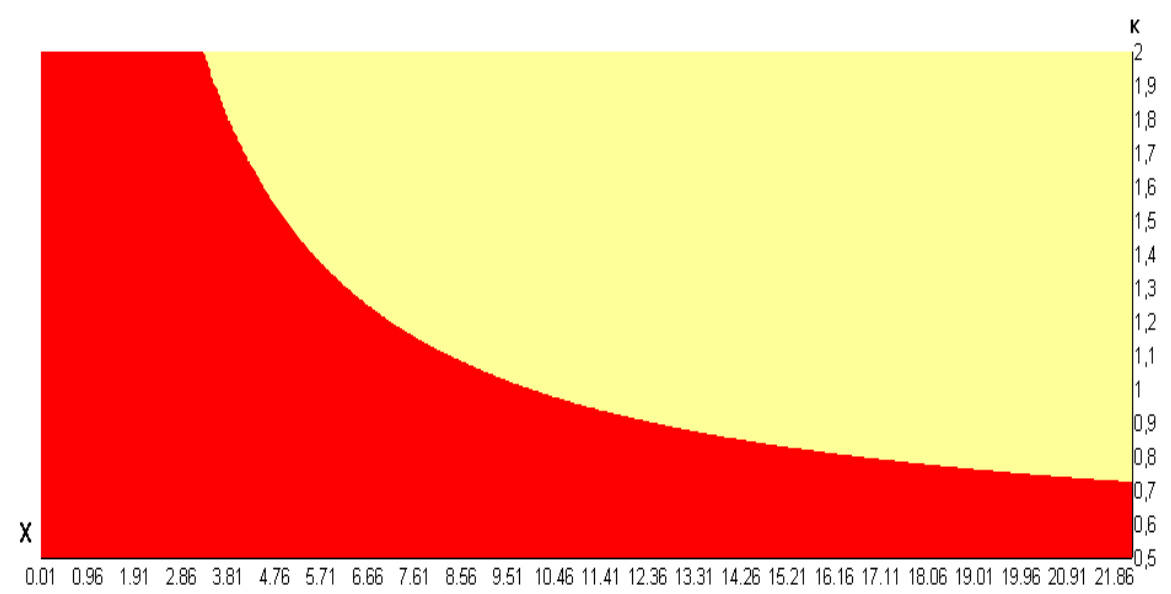

Figure 4: Gift making condition

Denoting $\varphi=e_{i} / X$, conditions (18) and (19) can be rewritten thus:

$$
\begin{gathered}
\frac{\varphi+1}{2} \geq \kappa \text { or } \varphi=e_{i} / X \geq 2 \kappa-1 \\
4 \kappa(\varphi X) X^{1 / 3}-X^{4 / 3}-3(\varphi X)^{4 / 3}(2 \kappa-1)^{2 / 3} \\
=4 \kappa \varphi-3 \varphi^{4 / 3}(2 \kappa-1)^{2 / 3}-1 \geq 0
\end{gathered}
$$

It is then evident that, when $\kappa=\varphi=1$, the two conditions hold with strict equality. This means that, when sensitivities of the two agents to social esteem or shame are identical $(\kappa=1)$, and when the parameters measuring such sensitivities are exactly equal to $X=\alpha_{j}^{2} / \beta_{j}\left(e_{i}=e_{j}=X\right)$, the two agents are just indifferent between entering into an asymmetric gift exchange relationship and remaining autarkic. It can then be shown that if $\kappa$ is varied marginally around unit value while $\varphi$ is adjusted so that the gift-making condition stays satisfied with strict equality, the gift-receiving condition (19') is necessarily vio- 
lated when $\kappa>1$. By contrast, when $\kappa$ is lowered marginally below one, and $\varphi$ is adjusted in the aforementioned manner, condition (19') holds, yet is no more binding: agent $i$ is just indifferent between making the gift and not making it while agent $j$ strongly prefers the patronage relationship to autarky. Moreover, the conclusion that the domain where $\kappa>1$ is infeasible holds a fortiori true if agent $i$ is assumed to have a strong rather than a weak preference for patronage compared to autarky - (18') is not binding (see Appendix A.3 for the complete proof).

Combining this finding with the earlier result that $e_{j} / e_{i}>1 / 2$ if agent $i$ is to agree to make a gift to agent $j$, we see that a patronage relationship may be established only in the restricted domain where the ratio of esteem parameters, $\kappa$, belongs to $\left[\frac{1}{2} ; 1\right]^{7}$.

In Figure (6), we show, in the three-dimensional space, and for $e_{i}=5$, how the net value of the recipient's utility - equal to his gross utility minus his stand alone-utility - varies depending on the values taken by $X$ and $\kappa$. This allows us to define the set of parameter values for which the recipient enjoys maximum utility. The Figure shows the domain of mutual profitability of the gift which corresponds to the shaded triangle-like area corresponding to $\kappa$-values smaller than 1 (and higher than 1/2). It is then apparent that the highest level of utility is attained by agent $j$ when his esteem coefficient is the lowest in the acceptable range. This result can be proven formally (see Appendix A.4). More caution is

\footnotetext{
${ }^{7}$ By analogy, we can conlude that agent $j$ will want to make a gift acceptable to agent $i$ only when $\kappa \in[1 ; 2]$.
} 


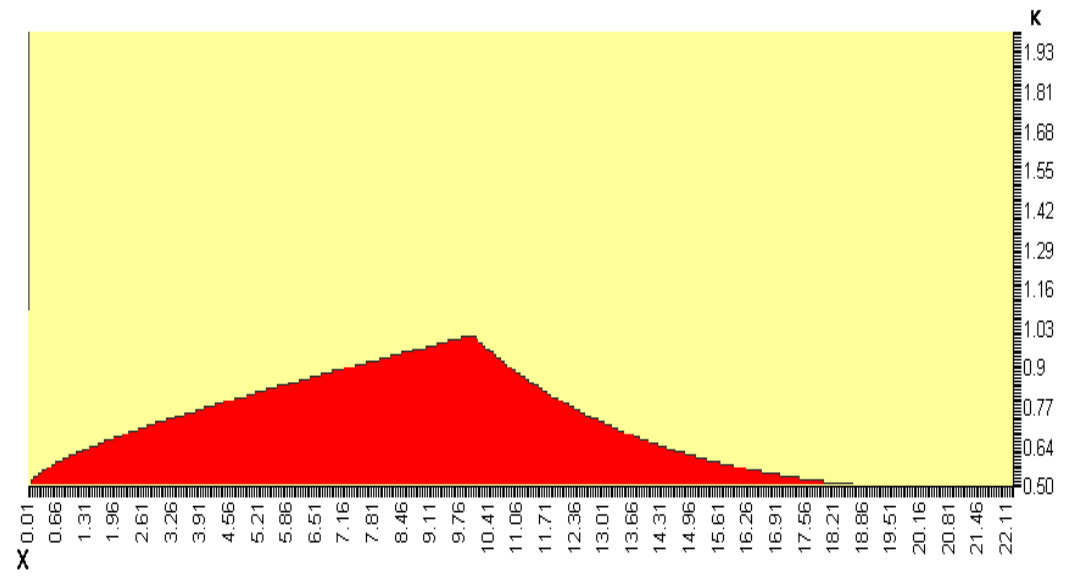

Figure 5: Feasibility of asymmetric gift exchange $\left(e_{i}=10\right)$

needed when addressing the question of the most desirable values of $X$. Indeed, as we can find by differentiating $j$ 's net utility with respect to $X$ and setting it equal to zero ${ }^{8}$, these values vary with the assumed magnitude of $e_{i}$. Indeed, the first-order condition obtained is written: $X^{*}=\left(e_{i}\left(2 e_{j}-e_{i}\right)\right)^{2}=e_{i}(2 \kappa-1)^{1 / 2}$, from which it is evident that $\partial X^{*} / \partial e_{i}>0$, for a given $\kappa$. In words, the larger the weight put on social prestige by the donor, the higher the recipient's productivity must be to afford him maximum utility from receiving a gift from the former. The intuition behind this new result is as follows: the more productive agent $j$, the more likely he is to accept a gift from a generous agent whose utility depends heavily on social esteem, since he is better able to respond to the gift by increasing his own production.

\footnotetext{
${ }^{8}$ Bear in mind that the net utility obtained by agent $j$ is given by $f(X)=4 \kappa e_{i}-X-$ $3 e_{i}^{4 / 3}\left(\frac{(2 \kappa-1)^{2}}{X}\right)^{1 / 3}$
} 


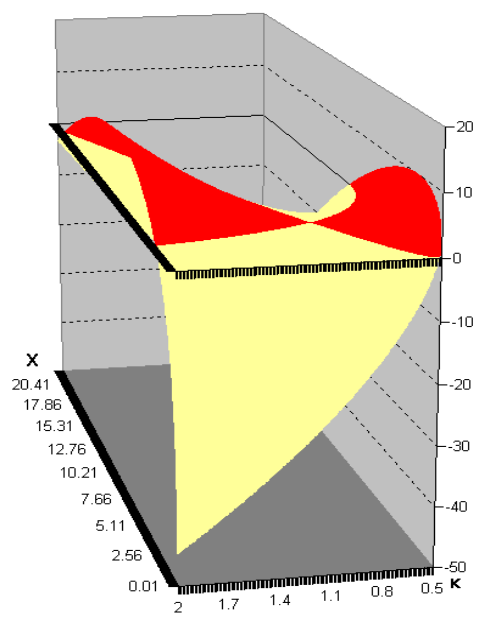

Figure 6: Gift acceptability condition $\left(e_{i}=5\right)$

The proposition below summarizes our main results:

Proposition 1 An asymmetric gift exchange relationship can be established only if the importance attached to social shame by the recipient is smaller, yet not too much smaller, that the importance attached to social esteem by the donor. From the standpoint of the recipient, maximum utility is obtained when the weight of shame is as low as possible. The potential donor is more likely to make a gift if his utility is more greatly influenced by social esteem considerations.

\section{$5 \quad$ Further results}

Before concluding the paper, three interesting questions deserve to be answered.

First, is it conceivable that patronage relationships are established between two 
agents of identical productivities (and effort costs)? Second, may reciprocal gifts be exchanged in the presence of social esteem and shame? Third, does aggregate output increases, decreases, or remain constant when autarky gives rise to patronage? We address these three questions successively.

We can show that the answer to the first question is positive within our analytical framework. The easiest way is to construct an example in which agents $i$ and $j$ have similar levels of effort productivity and $\operatorname{cost}\left(\alpha_{i}^{2} / \beta_{i}=\right.$ $\left.\alpha_{j}^{2} / \beta_{j}=9\right)$. Assuming that $\kappa=e_{j} / e_{i}=0.6$ and that $e_{i}=10$, we find that the two conditions for the feasibility of asymmetric gift exchange, conditions (18) and (19), are satisfied. Moreover, we verify that an interior solution is obtained: as a matter of fact, the condition $\alpha_{i}^{2} / \beta_{i}>\alpha_{i} t_{i}$ is fulfilled, ensuring that agent $i$ produces enough to have a positive amount of private consumption (see Appendix A.5 for a series of simulations confirming the above result). In fact, it is even possible that agent $j$, who accepts a gift made by agent $i$, has a (moderately) higher productivity.

This is an important result since the common view prevails that, for patronage to exist, there must be a dominating party, the patron, who is more productive than the dominated one, the client, typically because he is better endowed with wealth or productive resources. Our claim, here, is that a difference in social esteem coefficients is sufficient to produce patronage even between individuals of identical abilities. In other words, a person can accept an inferior position on the social ladder only because of a rather low sensitivity to the negative esteem that an humble position entails. It bears emphasis, however, that 
such a situation is a particular case that arises only for specific configurations of the esteem and productivity parameters. Hence our next proposition:

Proposition 2 An asymmetric gift exchange relationship, in which income is traded against social esteem or political power, can sometimes arise between two agents endowed with the same effort productivities, or in a situation where the recipient has a (moderately) higher productivity than the gift-maker. What is required is that the client is not too sensitive to social shame while the patron pays enough attention to social esteem.

Let us now turn to the second question. Here the answer turns out to be negative: in our model, it is not possible that the two agents are involved in a reciprocal exchange of gifts. This directly follows from the fact that the critical value of $\kappa$ (the ratio of esteem coefficients) above which an asymmetric transfer may not take place from agent $i$ to agent $j$ has been shown to be equal to one. This condition, which must be satisfied if a gift is to be made by agent $i$ and accepted by agent $j$, is logically contradictory with the inverse condition that $1 / \kappa<1$, which is necessary for a gift to be made by agent $j$ and accepted by agent $i$. Our analytical framework based on social esteem considerations, is, therefore, not appropriate to understand mechanisms of reciprocal, symmetrical, gift exchanges. As underlined in the first two sections, our concern is with asymmetrical social relationships in which an agent is subordinated to another agent and somehow accepts this situation.

Finally, there is the question of the variation of aggregate output between autarky and patronage. We know already that the donor produces exactly the 
same amount of output under the two systems. As a consequence, to answer the third question, we just have to look at the output response on the part of the potential donee.

His effort when receiving a gift is given by equation (13). Replacing $\gamma$ by $1 / 2$ in this expression and comparing it to the stand alone effort of agent $j$ (which is equivalent to effort defined by equation (5)), we derive the following condition under which he reduces his level of effort after entering into a patron-client relationship:

$$
1 / 2\left(X\left(2 e_{j}-e_{i}\right) e_{i}\right)^{1 / 3}<X / 2
$$

Using the above-defined notations, this condition becomes:

$$
(2 \kappa-1) \varphi^{2}<1
$$

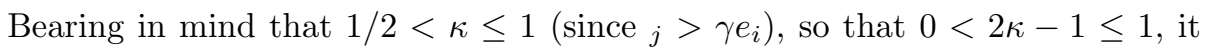
is evident that no upper bound for the $\varphi$ parameter can be determined. The only clear result is that condition (20) always holds when $\varphi \leq 1$ or $e_{i} \leq X$. When $\varphi>1$, the sign of the inequality is ambiguous and the variation of aggregate output cannot be known. This said, three meaningful effects come out of condition (20). To begin with, bearing in mind that $\kappa=e_{j} / e_{i}$, it is evident that the lower $e_{j}$, the higher the likelihood that the above condition is satisfied. The interpretation is as follows: if the beneficiary of the gift has a low sensitivity to social shame, he will not be keen to exert much effort to avoid it and, therefore, will be more likely to relax upon entering a patron-client relationship. 
Moreover, keeping in mind that $\varphi=e_{i} / X$ and $X=\alpha_{j}^{2} / \beta_{j}$, relaxation of effort on the part of agent $j$ is more likely to occur if, ceteris paribus, his productivity is higher. This is because, as we have seen earlier (see supra, section 3.2), productivity and effort are substitutes for the agent who benefits from the transfer. When the recipient's productivity increases, the utility of the donor decreases because the dependence of $j$ is reduced for a given amount of the gift. The donor responds by reducing the gift, and the beneficiary counters this move by relaxing his effort so as to increase his degree of dependence vis à vis the donor.

Finally, rewriting condition $(20)$ as $1 / X^{2}\left(2 e_{j} e_{i}-e_{i}^{2}\right)<0$, and bearing in mind that $e_{j} \leq e_{i}$ in the feasible domain, it is apparent that an increase in $e_{i}$ has the effect of relaxing the constraint. This means that the output of the beneficiary is more likely to decrease when the donor pays more attention to social esteem. It is interesting to notice that, in the feasibility domain, the above-noted indeterminacy of the sign of the partial derivative of $x_{j}$ and $\alpha_{j} x_{j}$ with respect to $e_{i}$ no more exists. Indeed, using (16) together with the definitions of $X$ and $\kappa$, the equilibrium output of agent $j$ can be written as $\frac{1}{2}\left(X e_{i}^{2}(2 \kappa-1)\right)^{1 / 3}$. The partial derivative of this expression with respect to $e_{i}$ can be shown to be: $\frac{\partial \alpha_{j} x_{j}}{\partial e_{i}}=\frac{1}{3}\left(\frac{X}{e_{i}(2 \kappa-1)^{2}}\right)^{1 / 3} \cdot(\kappa-1)$. Since we know that the feasibility domain is such that $\kappa \in[1 / 2 ; 1]$, the sign of this expression is unambiguously negative. The underlying rationale is that, when agent $i$ is more sensitive to social esteem, he is inclined to make a larger gift to agent $j$, and the latter responds by reducing his effort and output. This negative reaction 
is actually the net outcome of two effects running into opposite directions with the first effect outweighing the second one. On the one hand, enjoying a larger transfer, $j$ is induced to exert less effort himself but, on the other hand, he is also eager to mitigate the increase in social shame that this larger transfer entails, and the way to do that is to increase his own level of effort.

We can now write our last proposition.

Proposition 3 The establishment of an asymmetric gift exchange relationship is more likely to cause a reduction of output on the part of the recipient and, thereby, a reduction of total output if: (i) the recipient is less sensitive to social shame; (ii) his productivity is higher (or his effort cost is lower); and (iii) the donor is more sensitive to social esteem.

\section{Conclusion and application}

The central result obtained in this paper is that an asymmetric gift exchange equilibrium can occur only if the importance attached to social shame by a recipient is smaller than that attached to social esteem by a donor. Moreover, an income transfer is more likely to be traded against social esteem, status, or power when the weight put on these attributes by the donor or patron is higher. Whether this condition is fulfilled may crucially hinge on the size and the composition of the audience witnessing the gift exchange. We also show that, depending on the configurations of the esteem coefficients of the two parties, the recipient's productivity may take on a rather wide range of values in the domain 
of feasibility of asymmetric gift exchange. Contrary to a commonly prevailing view, productivities might be identical between donor and donee. In fact, the productivity of the donee/client could even be (moderately) smaller than that of the donor/patron. It is moreover possible, but not certain, that the beneficiary of the transfer will reduce his effort. This is more likely to occur if he is not too sensitive to social shame (or the donor is sensitive enough to social esteem) or if his productivity is sufficiently high (or his effort cost is sufficiently low).

Note that there is an interesting parallel between the above results and those obtained in Platteau and Seki (2007). In this paper, indeed, sensitivity to social esteem/shame, assumed to be identical for both agents, must exceed a minimum threshold if the most able agent is to agree to make a transfer and benefit from the associated local status effect while it must not be too high lest the less able agent should prefer autarky to receiving the transfer and suffering from social shame.

Aid relationships offer an interesting application of the theory. It has been shown empirically that the destination of bilateral aid flows can largely be explained by geopolitical considerations rather than by the characteristics of recipient countries that reflect need or strong absorption capacity (e.g., quality of governance). What is at work is a patronage logic whereby a dominating rich country provides aid to a poor, dominated country in exchange for the latter's allegiance, or subordination.

Interestingly, not all developing countries enter into such patronage relationships with donor countries from the developed world. For some of them at least, 
in particular for big countries such as China and India, the cost of subordination seems to be too high to make them accept aid transfers (on a substantial scale). As convincingly argued by Janos (1982), self-esteem considerations also operate at the level of nations. What must be added is that all countries are not equally self-conscious or sensitive to a sense of national pride. This depends on the history of the nation which may largely determine the strength of its feelings of national identity, and the extent to which it wants to be respected by foreign entities. The fact that countries which are today reluctant to enter into aid dependence relationships may not have displayed such a reluctance in the past (think of China during the 1950s and India during the 1960s) attests that other variables are at play. Among these other variables are the levels of poverty and the need for aid on the part of the laggard countries - China and India, in the immediate post-war period, were of course much poorer and less technologically developed than they are today -, which in our model are reflected in the productivity parameters. Another consideration, which is not taken care of by our model, is the possible existence of competition among donor countries: India accepted large aid transfers from the United States and the Soviet Union partly because these two donor countries were rivalrous superpowers in the tense international context of the cold war. As a result, India did not become subordinated to either of them. By contrast, for ideological reasons, China accepted massive aid from the Soviet Union but no aid from the United States, as a result of which it became subordinated to the U.S.S.R. It is therefore not surprising that, after an escalating quarrel with its foreign benefactor, the aid relationship 
was disrupted in the summer of 1960 (Riskin, 1987, p.130-131).

Following the logic of our model, poor countries under continuous dependence vis-à-vis donor countries will produce less than they would under autarky if the cost of subordination is not acutely felt by them, and/or if some rich countries are eager to secure a clientele in the developing world. This is perhaps an important aspect of the aid dependence syndrome. 


\section{A Appendix}

\section{A.1 Logarithmic specification of the esteem component of utility}

When the esteem component of the utility function is a logarithmic function of the percentage by which the gift made by $i$ allows $j$ to increase his consumption (i.e. the same argument that we use throughout the paper and for which we provide a justification in the text), the maximization problem of the gift giver is given by:

$$
\operatorname{Max}_{x_{i}, t_{i}}\left\{\alpha_{i} x_{i}-\beta_{i}\left(x_{i}+t_{i}\right)^{2}+e_{i} \ln \left(\frac{\alpha_{j} x_{j}+\alpha_{i} t_{i}}{\alpha_{j} x_{j}}\right)\right\}
$$

The two FOCs are then:

$$
\begin{gathered}
\frac{\partial(.)}{\partial x_{i}}=0 \Rightarrow \alpha_{i}=2 \beta_{i}\left(x_{i}+t_{i}\right) \\
\frac{\partial(.)}{\partial t_{i}}=0 \Rightarrow \frac{e_{i} \alpha_{i}}{\alpha_{j} x_{j}+\alpha_{i} t_{i}}=2 \beta_{i}\left(x_{i}+t_{i}\right)
\end{gathered}
$$

Combining these two conditions, we get:

$$
\alpha_{i} t_{i}=e_{i}-\alpha_{j} x_{j}
$$

Plugging this result in the second mover's (the recipient's) problem, we obtain:

$$
\begin{gathered}
\operatorname{Max}_{x_{j}}\left\{e_{i}-\beta_{j} x_{j}^{2}-e_{j} \ln \left(\frac{e_{i}}{\alpha_{j} x_{j}}\right)\right\} \\
\frac{\partial(.)}{\partial x_{j}}=0 \Rightarrow x_{j}=\sqrt{\frac{e_{j}}{2 \beta_{j}}}
\end{gathered}
$$




\section{A.2 Corner Solutions when the esteem component of the utility function is convex or linear}

\section{A.2.1 Convexity: $\gamma=2$}

When $\gamma=2$, meaning that the esteem component of the players' utility functions is convex, the F.O.C.s for the potential gift-giver (player $i$ ) are the following:

$$
\begin{gathered}
\frac{\partial U_{i}}{\partial x_{i}}=\alpha_{i}-2 \beta_{i}\left(x_{i}+t_{i}\right) \\
\frac{\partial U_{i}}{\partial t_{i}}=-2 \beta_{i}\left(x_{i}+t_{i}\right)+\frac{2 e_{i} \alpha_{i}\left(\alpha_{j} x_{j}+\alpha_{i} t_{i}\right)}{\left(\alpha_{j} x_{j}\right)^{2}}
\end{gathered}
$$

After setting them both equal to zero and combining them, we can derive the equilibrium levels of effort of player $i$ for own consumption and for gift transfer:

$$
\begin{gathered}
x_{i}=\frac{\alpha_{i}^{2}}{2 \beta_{i}}-\frac{1}{\alpha_{i}}\left[\frac{\left(\alpha_{j} x_{j}\right)^{2}}{2 e_{i}}-\alpha_{j} x_{j}\right] \\
t_{i}=\frac{1}{\alpha_{i}}\left[\frac{\left(\alpha_{j} x_{j}\right)^{2}}{2 e_{i}}-\alpha_{j} x_{j}\right]
\end{gathered}
$$

Replacing the best response of $i$ in terms of gift transfer in the maximization problem of the recipient, $j$, and optimizing with respect to $x_{j}$, we obtain:

$$
\frac{\partial U_{j}}{\partial x_{j}}=\frac{2 \alpha_{j}^{2} x_{j}}{2 e_{i}}\left(2 e_{i}-e_{j}\right)-2 \beta_{j} x_{j} \lessgtr 0 \Rightarrow \frac{2 \alpha_{j}^{2}}{2 e_{i}}\left(2 e_{i}-e_{j}\right)-2 \beta_{j} \lessgtr 0
$$

When the LHS is smaller to zero, we have the corner solution $x_{j}=0$ : agent $j$ behaves in a parasitic fashion as a result of which agent $i$ refuses to make a gift. On the other hand, when the LHS is positive, the would-be recipient has an incentive to always increase his effort, $x_{j}^{o} \rightarrow \infty$.

In the latter case, the gift-maker will dedicate all his effort to producing the gift: $t_{i}^{o}=\alpha_{i} / 2 \beta_{i}$ and $x_{i}=0$ 


\section{A.2.2 Linearity: $\gamma=1$}

When $\gamma=1$, the esteem component of the players' utility functions is linear.

The F.O.C.s for the potential gift-giver (player $i$ ) are the following:

$$
\begin{gathered}
\partial U_{i}(.) / \partial x_{i}=\alpha_{i}-2 \beta_{i}\left(x_{i}+t_{i}\right)^{2}=0 \\
\partial U_{i}(.) / \partial t_{i}=-2 \beta_{i}\left(x_{i}+t_{i}\right)^{2}+\frac{\alpha_{i} e_{i}}{\alpha_{j} x_{j}}=0
\end{gathered}
$$

Combining these two conditions, we get that $\alpha_{j} x_{j}=e_{i}$. It is therefore impossible to determine the equilibrium values of $x_{i}$ and $t_{i}$ from the above two FOCs. What we have is a corner solution in which either agent $i$ produces only for the sake of providing a gift to agent $j\left(e_{i}>\alpha_{j} x_{j}\right)$, or in which i produces only for his own consumption $\left(e_{i}<\alpha_{j} x_{j}\right)$.

\section{A.3 Feasibility of asymmetric gift exchange: the restric- tion on $\kappa$}

Let us vary $\kappa$ marginally around unit value. It is immediately evident that condition (18') remains satisfied only if $\varphi$ undergoes an even larger variation than $\kappa$. Knowing this, we must examine how condition (19') evolves. What we show is that the LHS of (19') becomes negative when $\kappa>1$ : the potential donee will not accept the gift if he is more sensitive to social shame than the donor is to social esteem or prestige. To prove this, let us denote the LHS of (19') by $\Psi$, bearing in mind that $\varphi=(2 \kappa-1)$ when $\left(18^{\prime}\right)$ is binding: $\Psi=4 \kappa \varphi-3 \varphi^{2}-1$. Since $\varphi=2 \kappa-1$, we infer that $d \varphi / d \kappa=2$ when we vary $\kappa$ marginally around 
the unit value. We can then write that:

$$
d \Psi=4 \varphi d \kappa+(4 \kappa-6 \varphi) 2 d \kappa
$$

Or:

$$
d \Psi / d \kappa=-8 \varphi+8 \kappa=8(1-\kappa)
$$

once we use again the property that $\varphi=2 \kappa-1$. This expression is obviously negative when $\kappa>1$ :

$$
d \Psi / d \kappa \lesseqgtr 0 \Leftrightarrow \kappa \gtreqless 1
$$

When $\kappa$ increases marginally above $1, \Psi$ will decrease and condition (19') is violated. On the other hand, when $\kappa$ is lowered marginally below one, condition (19') is satisfied and is no more binding: agent $j$ now strongly prefers the patronage relationship to autarky.

To complete the proof, we want to check whether the above result holds a fortiori when we assume that agent $i$ strongly prefers patronage to autarky. Starting again from the benchmark case where $\kappa=\varphi=1$, and adjusting $\varphi$ to $\kappa$ so that (18') is no more binding, we find that condition (19') can be satisfied only in the domain where $\kappa<1$. The proof is as follows. We start from the situation where $\varphi=2 \kappa-1$ and shift to a new situation where $\varphi>2 \kappa-1$, or $\kappa<(\varphi+1) / 2$. We, therefore, assume that $d \varphi=2 \delta d \kappa$, with $\delta>1$. We can then write:

$$
d \Psi=4 \varphi d \kappa+(4 \kappa-6 \varphi) 2 \delta d \kappa
$$

so that

$$
\frac{d \Psi}{d \kappa}=4 \varphi(1-3 \delta)+8 \delta \kappa
$$


For this expression to be positive, we must have that $\kappa \geq \frac{\varphi}{2}\left(3-\frac{1}{\delta}\right)$. Since $\delta>1$ and, hence, $\left(3-\frac{1}{\delta}\right)>2, \kappa$ exceeds $\varphi$ to an even larger extent than in the vicinity of $\kappa=1$, where (18') continues to be binding. We now have the following two conditions: $\kappa>\varphi$ and $\kappa<(\varphi+1) / 2$, which can never be simultaneously satisfied if $\kappa \geq 1$. On the other hand, if $\kappa<1$, the two above conditions can possibly be satisfied depending on the values of the two parameters (the gap between $\kappa$ and $\varphi$ must not be too large).

\section{A.4 Optimal characteristics for gift acceptance}

The individual whose utility is the highest when receiving a gift is the one for whom the following expression, which is derived from (19), is maximized with respect to $X$ :

$$
f(X)=4 \kappa e_{i}-X-3 e_{i}^{4 / 3}\left(\frac{(2 \kappa-1)^{2}}{X}\right)^{1 / 3}
$$

Taking the first order w.r.t. $X$, and setting it equal to zero, we obtain that $X^{*}=e_{i}(2 \kappa-1)^{1 / 2}=\left(e_{i}\left(2 e_{j}-e_{i}\right)\right)^{1 / 2}$. This value does maximize $f(X)$ because $f^{\prime}(X)>0$ and $f^{\prime \prime}(X)<0$. Plugging this value $\mathrm{f}(\mathrm{X})$, we have that :

$$
f\left(X^{*}\right)=4 \kappa e_{i}-e_{i}(2 \kappa-1)^{1 / 2}-3 e_{i}(2 \kappa-1)^{1 / 2}=\kappa-(2 \kappa-1)^{1 / 2}
$$

We can then infer that:

$$
f\left(X^{*}\right) \geq 0 \Rightarrow \kappa^{2}-2 \kappa+1 \geq 0
$$

which is true $\forall \kappa \geq 0$. We can, therefore, conclude that values of $\alpha_{j}$ and $\beta_{j}$ always exist such that, if $j$ receives a gift, he would accept it. 


\section{A.5 Simulation results for symmetric productivity param-}

\section{eters}

Up to here we have defined $X=\alpha_{j}^{2} / \beta_{j}$. Let us now index $X$ so that $X_{j}=\alpha_{j}^{2} / \beta_{j}$ and $X_{i}=\alpha_{i}^{2} / \beta_{i}$.

Here below, we provide the reader with a series of simulations of efforts applied by agent $i$ towards own consumption and towards gift transfer, and of effort applied by agent $j$, under specific conditions in which both agents are equally productive $\left(X_{i}=X_{j}\right)$. It is immediately evident that agent $i$ may make positive gifts to agent $j$ in the presence of identical effort productivities.

\begin{tabular}{rrrrrrrrrrrrr}
$e_{i}$ & $e_{j}$ & $\kappa$ & $\alpha_{i}$ & $\beta_{i}$ & $\alpha_{j}$ & $\beta_{j}$ & $X_{i}$ & $X_{j}$ & $\alpha_{i} t_{i}$ & $\alpha_{i} x_{i}$ & $\alpha_{j} x_{j}$ & $\alpha_{j} x_{j}+\alpha_{i} t_{i}$ \\
\hline 10 & 9 & 0.9 & 1 & 0.05 & 1 & 0.05 & 20 & 20 & 6.5 & 3.5 & 2.71 & 9.21 \\
10 & 7 & 0.7 & 1 & 0.05 & 1 & 0.05 & 20 & 20 & 9.45 & 0.55 & 2.15 & 11.6 \\
5 & 4 & 0.8 & 1 & 0.1 & 1 & 0.1 & 10 & 10 & 2.47 & 2.53 & 1.55 & 4.02 \\
5 & 3 & 0.6 & 1 & 0.1 & 1 & 0.1 & 10 & 10 & 4.72 & 0.28 & 1.08 & 5.8 \\
1 & 0.8 & 0.8 & 1 & 1.25 & 1 & 1.25 & 0.8 & 0.8 & 0.25 & 0.15 & 0.39 & 0.64 \\
1 & 1 & 1 & 1 & 2 & 1 & 2 & 0.5 & 0.5 & 0.23 & 0.02 & 0.4 & 0.63 \\
0.5 & 0.4 & 0.7 & 1 & 1.67 & 1 & 1.67 & 0.6 & 0.6 & 0.01 & 0.29 & 0.25 & 0.25 \\
0.5 & 0.4 & 0.8 & 1 & 2.5 & 1 & 2.5 & 0.4 & 0.4 & 0.01 & 0.19 & 0.25 & 0.25 \\
\hline
\end{tabular}




\section{References}

[1] G. Akerlof. Labor contracts as partial gift exchange. Quarterly Journal of Economics, 87 (4):543-569, 1982.

[2] P. Alexander. Sri Lankan Fishermen -Rural Capitalism and Peasant Society. Canberra: Australian National University Press, 1982.

[3] A. Aoki. Toward a Comparative Institutional Analysis. The MIT Press, Cambridge, Msstts \& London, 2001.

[4] V. Barham, R. Boadway, M. Marchand, and P. Pestieau. Volunteer work and club size: Nash equilibrium and optimality. Journal of Public Economics, 65:9-22, 1997.

[5] C. Belshaw. Traditional Exchange and Modern Markets. Prentice-Hall, Englewoods Cliffs, NJ, 1965.

[6] D. Bernheim, A. Shleifer, and L. Summers. The strategic bequest motive. Journal of Political Economy, 93 (6):1045-1076, 1985.

[7] P. Blau. Exchange and Power in Social Life. John Wiley and Sons, 1964.

[8] P. Bourdieu. The Logic of Practice. Stanford University Press, Stanford, Cal., 1990.

[9] J. Breman. Patronage and Exploitation - Changing Agrarian Relations in South Gujarat. University of California Press, Berkeley, CA, 1974. 
[10] G. Brennan and P. Pettit. The Economy of Esteem - An Essay on Civil and Political Society. Oxford University Press, Oxford, 2005.

[11] H.L. Carmichael and W.B. MacLeod. Gift giving and the evolution of cooperation. International Economic Review, 38 (3):485-509, 1997.

[12] A. E. Clark and A. J. Oswald. Comparison-concave utility and following behaviour in social and economic settings. Journal of Public Economics, 70 (1):133-155, 1998.

[13] S. Coate and M. Ravallion. Reciprocity without commitment: Characterization and performance of informal insurance arrangements. Journal of Development Economics, 40 (1):1-24, 1993.

[14] D. Cox and M. R. Rank. Inter-vivos transfers and intergenerational exchange. The Review of Economics and Statistics, 74 (2):305-314, 1992.

[15] D. Cox and O. Stark. Bequests, inheritances and family traditions. CPR WP 2005-09, Center for Retirement Research, Boston College, MA, 2005.

[16] S. Dercon and P. Krishnan. In sickness and in health: Risk-sharing within households in ethiopia. Journal of Political Economy, 108 (4):688-727, 2000.

[17] T.S. Epstein. Capitalism, Primitive and Modern - Some Aspects of Tolai Economic Growth. Australian University Press, Canberra, 1968. 
[18] E. E. Evans-Pritchard. The Nuer: A Description of the Modes of Livelihood and Political Institutions of a Nilotic People. Clarendon Press, Oxford, 1940.

[19] M. Fafchamps. Solidarity networks in preindustrial societies: Rational peasants with a moral economy. Economic Development and Cultural Change, 41 (1):147-174, 1992.

[20] E. Fehr and S. Gächter. Fairness and retaliation: The economics of reciprocity. Journal of Economic Perspectives, 14 (3):159-181, 2000.

[21] E. Fehr, G. Kirschsteiger, and A. Riedl. Gift exchange and reciprocity in competitive experimental markets. European Economic Review, 42 (1):134, 1998.

[22] D.M.T. Fessler. The Role of Shame and Self-Esteem in Risk-Taking, pages 191-214. in Gigerenzer, G. and R. Selten (eds), The MIT Press, Cambridge, Mssts, and London, 2001.

[23] B.R. Finney. Big-Men, Half-Men and Trader-Chiefs: Entrepreunial Styles in Australian New Guinea and French Polynesia, pages 114-130. in Epstein, T.S. and D.H. Penny (eds), C. Hurst \& Company, London, 1972.

[24] R. Frank. Choosing the Right Pond: Human Behavior and the Quest for Status. Oxford University Press, Oxford, 1985.

[25] R. Frank. Passions Within Reason: The Strategic Role of Emotions. W.W.Norton \& Company, New York, 1989. 
[26] S. Gächter and E. Fehr. Collective action as social exchange. Journal of Economic Behavior and Organization, 39:341-369, 1999.

[27] F. Gaspart and E. Seki. Cooperation, status seeking and competitive behaviour. Journal of Economic Behaviour and Organization, 51 (1):51-77, 2003.

[28] C.A. Gregory. Gifts and Commodities. Academic Press, Cambridge, 1982.

[29] J. Hoddinott. Rotten kids or manipulative parents: Are children old age security in western kenya? Economic Development and Cultural Change, 40:545-566, 1992.

[30] H. Holländer. A social exchange approach to voluntary cooperation. The American Economic Review, 80 (5):1157-1167, 1990.

[31] B. Holmstrom and P. Milgrom. Multitask principal-agent analyses: Incentive contracts, asset ownership, and job design. Journal of Law, Economics and Organization, 7:24-52, 1991.

[32] G.C. Homans. Social Behavior: Its Elementary Forms. Harcourt, Brace \& World, New York, 1961.

[33] D. Hume. A Treatise of Human Nature. Clarendon Press, edited by L.A. Selby-Bigge, Oxford, 1888 (second edition 1978).

[34] A. C. Janos. The Politics of Backwardness in Hungary, 1825-1945. Princeton University Press, Princeton, New Jersey, 1982. 
[35] P. Johnson, D.K. Levine, and W. Pesendorfer. Evolution and information in a gift-giving game. Journal of Economic Theory, 100:1-21, 2001.

[36] M.S. Kimball. 'farmers' cooperatives as behavior toward risk. American Economic Review, 78 (1):224-232, 1988.

[37] H. Levi-Strauss. The Elementary Structures of Kinship. Social Science Paperbacks (Revised Edition), London, 1969.

[38] E.J.P.T. Ligon and T. Worall. Informal insurance with limited commitment: Theory and evidence from village economies. Review of Economic Studies, 69 (1):209-244, 2002.

[39] B. Malinowski. Argonauts of the Western Pacific -An Account of Native Entreprise and Adventure in the Archipelagoes of Melanesian New Guinea. Routledge (Reprinted 1999), London, 1922.

[40] M. Mauss. The Gift. Routledge, London, 1925 (reprinted 1990).

[41] J. Morduch. Between the market and the state: Can informal insurance patch the safety net? World Bank Research Observer, 14 (2):187-207, 1999.

[42] A. Offer. Between the gift and the market: The economy of regard. Economic History Review, 50 (3):450-476, 1997.

[43] C. Paxson. Consumption and income seasonality in thailand. Journal of Political Economy, 101 (1):39-72, 1993. 
[44] J. Pitt-Rivers. The People of Sierra. Weidenfield and Nicolson, London, 1954.

[45] J.P. Platteau. Traditional Systems of Social Security and Hunger Insurance: Past Achievements and Modern Challenges, pages 112-170. Clarendon Press, Oxford, 1991.

[46] J.P. Platteau. A framework for the analysis of evolving patron-client ties in agrarian economies. World Development, 23 (5):767-786, 1995.

[47] J.P. Platteau. An indian model of aristocratic patronage. Oxford Economic Papers, 47 (4):636-662, 1995.

[48] J.P. Platteau and E. Seki. Heterogeneity, social esteem, and feasibility of collective action. Journal of Development Economics, forthcoming, 2007.

[49] K. Polanyi. The Great Transformation. Rinehart, New York, 1944.

[50] K. Polanyi. Primitive, Archaic, and Modern Economics. Doubleday, New York, 1968.

[51] C. Riskin. China's Political Economy - The Quest for Development since 1949. Oxford University Press, Oxford, 1987.

[52] H. Robben and T. Verhallen. Behavioral costs as determinants of cost perception and preference formation for gifts to receive and gifts to give. Journal of Economic Psychology, 15:333-350, 1994.

[53] M. Sahlins. Political Power and the Economy in Primitive Society. Cromwell, New York, 1960. 
[54] M. Sahlins. Poor man, rich man, big man: Political types in melanesia and polynesia. Comparative Studies in Society and History, 5, 1963.

[55] M. Sahlins. Stone Age Economics. Aldine, Chicago, 1974.

[56] B. Schwartz. The social psychology of the gift. The American Journal of Sociology, 73 (1):1-11, 1967.

[57] J. Scott. The Moral Economy of the Peasant. Yale University Press, New Haven, CT, 1976.

[58] R.M. Townsend. Risk and insurance in village india. Econometrica, 62 (3):539-591, 1994.

[59] C. Udry. Risk and insurance in a rural credit market: An empirical investigation in northern nigeria. Review of Economic Studies, 61:495-526, 1994.

[60] J. Van de Ven. The demand for social approval and status as a motivation to give. Journal of Institutional and Theoretical Economics, 158 (3):464482, 2002.

[61] R. Wintrobe. The Political Economy of Dictatorship. Cambridge University Press, Cambridge, 1998. 